\title{
Development of Self-Stabilizing Links for Eccentrically Braced Frames
}

\author{
Authors: \\ Jeffrey W. Berman, University of Washington, Dept. of CEE, Seattle, WA \\ jwberman@u.washington.edu \\ Michel Bruneau, University at Buffalo, Dept. of CSEE, Buffalo, NY \\ bruneau@buffalo.edu
}

\begin{abstract}
This paper highlights aspects of the development of self-stabilizing links having tubular cross-sections for use in eccentrically braced frames (EBF's). EBF's utilizing this type of link could be used in bridge piers or other applications where lateral bracing to prevent lateral torsional buckling is difficult to provide. The development of design recommendations for these types of links consisted of three parts, namely, a proof-ofconcept experiment, a finite element parametric study, and testing of links with various cross-sectional properties and lengths; the latter two parts are discussed in this paper. The finite element parametric study involved over 200 links with various cross-sections, lengths, and yield strengths and resulted in recommendations for compactness ratio limits for webs and flanges of links with tubular cross-sections which were valid for a range of typical steel yield strengths. Links with three different tubular cross-sections having compactness ratios near and well below the proposed limits were then investigated experimentally. These links also had various lengths covering the full range of link behavior (i.e., shear to flexural dominated yielding). Fourteen links in total were tested. The results indicated that the proposed design recommendations were adequate to ensure tubular links can achieve plastic rotation levels equivalent to the maximum allowed for wide-flange links considering the loading protocol from the 2005 AISC Seismic Provisions.
\end{abstract}

\section{INTRODUCTION}

Eccentrically braced frames (EBF's), which rely on yielding of a link beam between eccentric braces, have been shown to provide ductility and energy dissipation under seismic loading (Roeder and Popov 1978a, Roeder and Popov 1978b, Popov and Bertero 1980, Hjelmstad and Popov 1983, Hjelmstad and Popov 1984, Malley and Popov 1984, Kasai and Popov 1986a, Kasai and Popov 1986b, Ricles and Popov 1989, and Engelhardt and Popov 1992, among others). Guidelines for EBF design with links having wideflange (WF) cross-sections are in the current AISC seismic provisions (AISC 2005). However, the use of WF shapes as link beams necessitates that they be braced out-of- 
plane to prevent lateral torsional buckling. This requirement has limited their use in bridge piers where lateral bracing is difficult to provide.

There have been some applications of EBF's with WF links in bridge piers for long span bridges such as the San Francisco-Oakland Bay Bridge and the Richmond-San Rafael Bridge (Dusicka et al., 2002, and Itani, 1997). In these cases, either very short links were used or special considerations for link stability were made, which may have increased the cost of the projects. Therefore, the development of a link type that does not require lateral bracing is desirable for application of EBF's in bridge piers. Such selfstabilizing links would also be useful in buildings where lateral bracing may not be feasible or easily provided. Furthermore, the design of EBF's to protect existing bridge pier bracing members may be employed using the approach in Berman and Bruneau (2005a), or EBF systems may be used to replace existing deficient pier brace systems.

This paper highlights aspects of the development of design recommendations for tubular links in eccentrically braced frames. Tube shapes are generally not subject to lateral torsional buckling at lengths typical of EBF links. Development of design recommendations for these types of links consists of three parts, namely, a proof-ofconcept experiment, a finite element parametric study, and testing of links with various cross-sectional properties and lengths; the latter two parts are briefly described in the sections below and details regarding the proof-of-concept testing can be found in Berman and Bruneau (2007).

\section{Finite Element Modeling}

A finite element model of the link from the proof-of-concept testing reported on in Berman and Bruneau (2007) was developed using the software package ABAQUS (HKS 2001). This model was developed using four-node reduced integration shell elements and employed nonlinear material and geometry. The material model selected had only kinematic hardening, i.e., it neglected the isotropic hardening component which is acceptable for steel at large strains (Berman and Bruneau 2006). The model parameters were fit to coupon test results of the web and flange material. A mesh refinement study was performed to determine the adequate mesh density. Comparing the link shear force versus rotation hysteresis curves in Fig. 1 shows reasonable agreement with the experimental results.

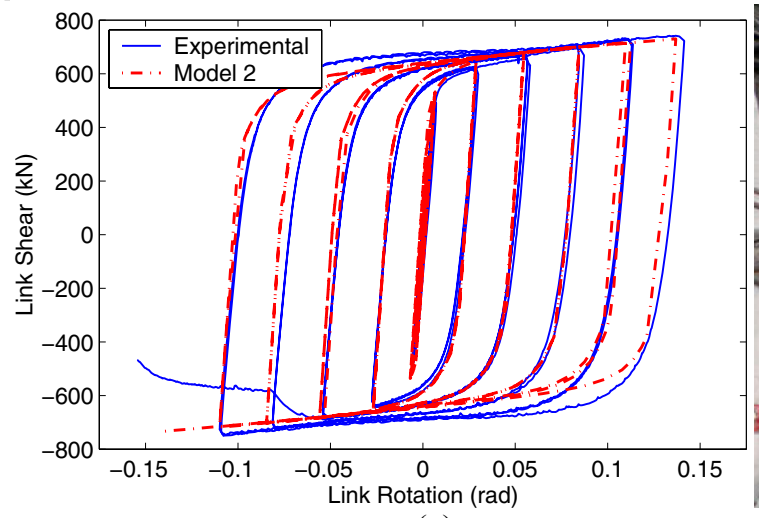

(a)

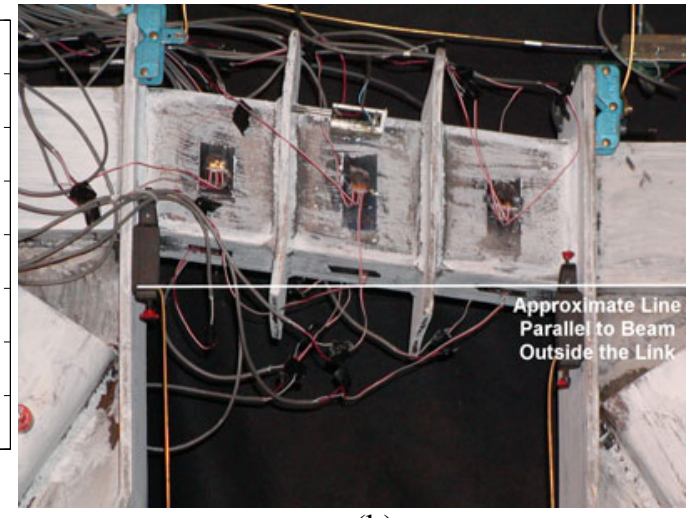

(b)

Figure 1. (a)Proof-of-Concept Link Hysteresis Curve (b) Deformed Link at -0.123 rads. 


\section{PARAMeTric STUdy}

Using the finite element model of the link from the proof-of-concept test as a basis, a parametric study of tubular links was performed. The parametric study consisted of two parts: Part 1 investigated links with a wide range of web and flange compactness ratios to assess the adequacy of the derived flange compactness ratio limit and stiffener spacing equation from Berman and Bruneau (2005b), and the results are used to modify those local buckling prevention criteria as necessary; Part 2 examined a range of web and flange yield stresses for links with webs and flanges having slendernesses close to the modified compactness ratio limits.

Four parameters were used to develop the 128 links in Part 1 of the parametric study: the normalized link length, $\rho$, the flange compactness ratio, $b^{\prime} t_{f}$ (where $b^{\prime}=b-2 t_{w}$ ), the web compactness ratio, $d^{\prime} / t_{w}$ (where $d^{\prime}=d-2 t_{f}$ ), and the stiffener spacing, $a$. Normalized link lengths representative of each yielding type, shear, intermediate, and flexural were desired. Therefore, $\rho=1.2,2.1$, and 3.0 were selected as they represent evenly spaced values of normalized link lengths well within all three ranges of expected behavior (delineated by the transition points of $\rho=1.6$ and $\rho=2.6$ for shear-to-intermediate and intermediate-to-flexural behaviors, respectively). A fourth length of $\rho=1.6$ was selected as it represents the longest links with a 0.08 rad plastic rotation limit as specified by AISC (AISC 2005). Flange compactness ratios of 8.0, 17.0, 24.0, and 40.0 and web compactness ratios of 12.0, 16.0, 24.0, and 36.0 were selected (Berman and Bruneau 2006). Both stiffened and unstiffened cases were considered, where the stiffener spacing satisfied the requirements in Berman and Bruneau (2005b). Loading for the models was that specified for link testing in the 2002 AISC Seismic Provisions (AISC 2002). Note that this loading protocol has been modified in the 2005 AISC Seismic Provisions (AISC 2005). The limit rotation for each link model was assumed to be the point where $20 \%$ degradation from the maximum link shear force occurred.

Example results from Part 1 of the parametric study are shown in Figs. 2a and 2b, which has limit rotation versus normalized link length for links that have $b^{\prime} / t_{f} \leq 17.0$. For reference, these figures also have a solid line indicating the AISC specified maximum rotation (also referred to as the target rotation).

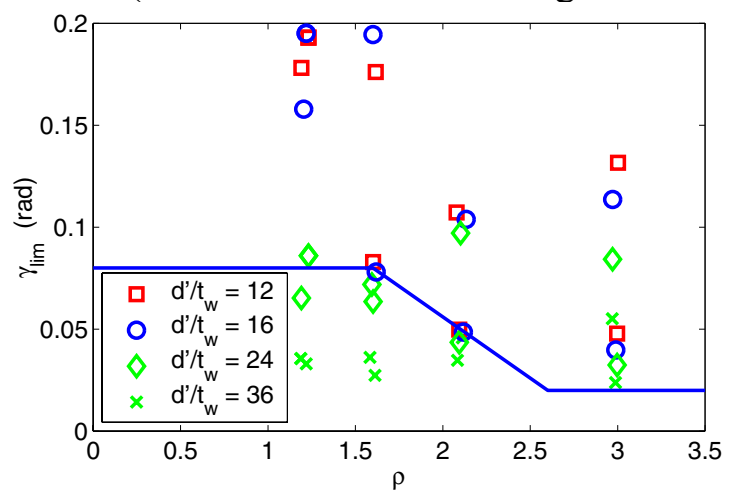

(a)

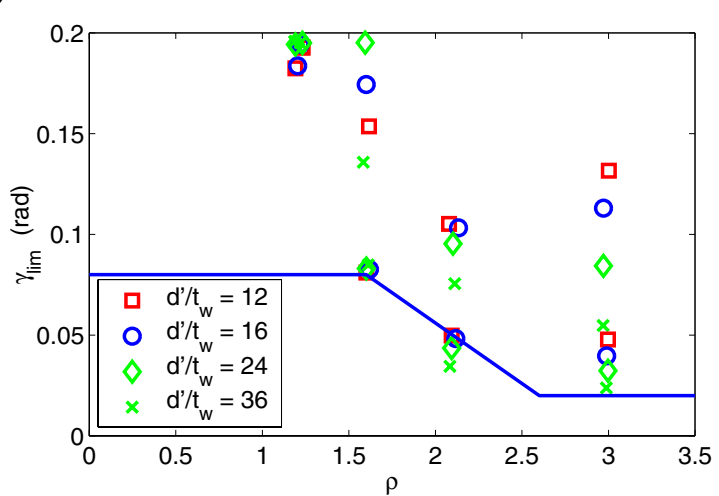

(b)

Figure 2. Limit Rotations for Links with $b^{\prime} / t_{f} \leq 17.0$ (a) Unstiffened (b) Stiffened.

Based on observations from Part 1 of the parametric study as described in Berman and Bruneau (2006) the following design recommendations below were developed: 
- All tubular links should have $b^{\prime} / t_{f} \leq 0.64 \sqrt{E_{s} / F_{y f}}$.

- For shear links $(\rho \leq 1.6)$, webs should be limited to $d^{\prime} / t_{w} \leq 1.67 \sqrt{E_{s} / F_{y w}}$ and webs meeting $d^{\prime} / t_{w} \leq 0.64 \sqrt{E_{s} / F_{y w}}$ may be used without stiffeners, where $d^{\prime}=d-2 t_{f}$.

- Stiffeners for webs of shear links with $0.64 \sqrt{E_{s} / F_{y w}} \leq d^{\prime} / t_{w} \leq 1.67 \sqrt{E_{s} / F_{y w}}$ should be provided at a spacing, a, satisfying:

$$
\frac{a}{t_{w}}+\frac{1}{8} \frac{d}{t_{w}}=C_{B}
$$

where $C_{B}$ is 20 and 37 for ultimate link rotations of 0.08 rads and 0.02 rads respectively.

- For intermediate and flexural links, web compactness should satisfy $d^{\prime} / t_{w} \leq 0.64 \sqrt{E_{s} / F_{y w}}$ and stiffeners are not required.

Since tubular links may be fabricated with four plates welded together, hybrid crosssections where the yield stresses of the webs and flanges are different could be used advantageously. Furthermore, the increased use of low yield point and high performance steels indicates a practical need for verifying the revised design requirements for a range of possible yield stresses. Part 2 of the finite element parametric study investigated the use of steels with yield stresses of $250 \mathrm{MPa}, 345 \mathrm{MPa}$, and $450 \mathrm{MPa}$ as these are representative of some of the steels currently available. The same normalized link lengths used in Part 1 of the study were used in Part 2 (i.e., $\rho$ values of 1.2, 1.6, 2.1, and 3.0). Link web and flange compactness ratios for Part 2 of the parametric study were within $1 \%$ of the proposed limits above. Results of Part 2 of the parametric study indicated that the proposed web and flange compactness ratio limits are applicable for the range of yield stresses considered (Berman and Bruneau 2006).

\section{LINK TESTING - SPECIMENS}

Twelve primary specimens, consisting of three link cross-sections and four link lengths, were selected for quasi-static cyclic testing. The three cross-sections, X1, X2, and X3 are given in Table 1 . Note the four normalized link lengths considered for each cross-section were 1.2, 1.6, 2.1, and 3.0, which were also used in the finite element parametric study. Link specimens are denoted by cross-section number and normalized length, i.e., Specimen X1L1.2 has cross-section type 1 and a normalized length of 1.2.

Table 1. Properties of Link Cross-Sections

\begin{tabular}{c|c|c|c|c|c|c|c|c} 
& $b(\mathrm{~mm})$ & $d(\mathrm{~mm})$ & $t_{f}(\mathrm{~mm})$ & $t_{w}(\mathrm{~mm})$ & $b^{\prime} / t_{f}$ & $d^{\prime} / t_{w}$ & $V_{p}(\mathrm{kN})$ & $M_{p}(\mathrm{kN}-\mathrm{m})$ \\
\hline $\mathrm{X} 1$ & 260 & 178 & 16 & 10 & 15.2 & 15.3 & 554 & 265.7 \\
$\mathrm{X} 2$ & 210 & 267 & 13 & 6 & 15.5 & 38 & 610 & 296.7 \\
$\mathrm{X} 3$ & 238 & 159 & 22 & 13 & 9.6 & 9 & 578 & 277.7 \\
\hline
\end{tabular}

As shown in the example elevation views of Specimens X1L1.2, X2L1.2, and $\mathrm{X} 3 \mathrm{~L} 1.2$, in Fig. 4, each primary link has a haunch at each end prior to the connection to an end-plate. Two supplementary links, AX1L1.6 and AX2L1.6 had the alternate end connection also shown in Fig. 4. Details regarding the test setup may be found in Berman and Bruneau (2006). 


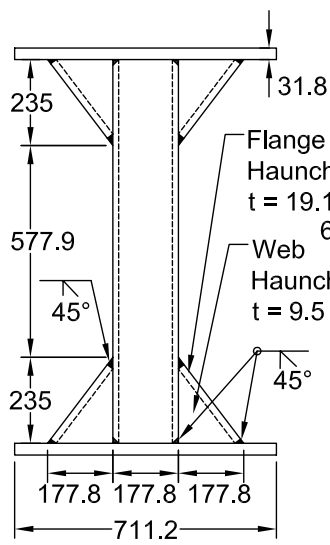

Specimen X1L1.2

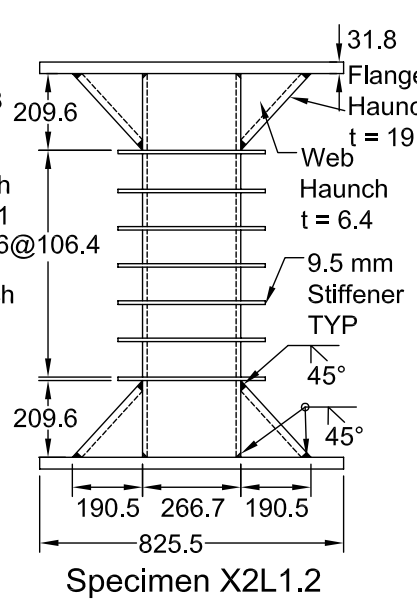

Specimen X2L1.2

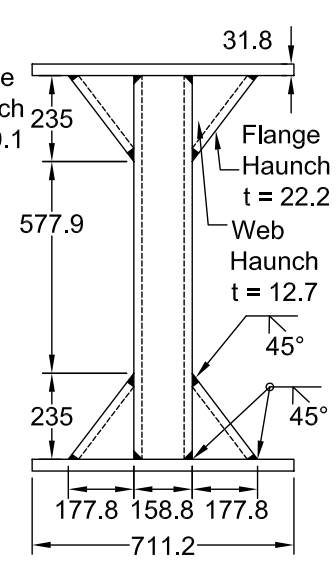

Specimen X3L1.2

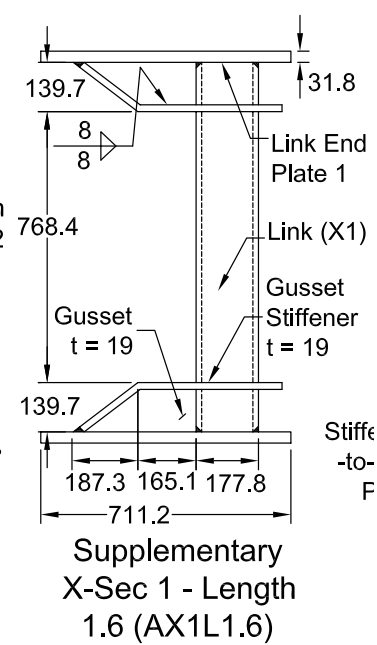

$1.6(\mathrm{AX} 1 \mathrm{~L} 1.6)$

Figure 4. Example Link Specimen Elevations

The loading protocol used for testing thirteen of the fourteen hybrid rectangular link specimens is the one specified by the 2002 AISC Seismic Provisions (AISC 2002). It is the same protocol, based on total link rotation, that was used for the links in the finite element parametric study described above. The supplementary link with cross-section 2 , Specimen AX2L1.6, was tested using the loading protocol specified in the recent 2005 AISC Seismic Provisions (AISC 2005). This protocol was developed by Richards and Uang (2003) considering tabulated cumulative plastic rotation and cumulative energy dissipation demand from various eccentrically braced frames subjected to many ground motions. The protocol requires more cycles at lower rotation levels and fewer cycles at larger rotations relative to the protocol of the 2002 Seismic Provisions. For links with normalized lengths of 1.2 or $1.6,2.1$, and 3.0 the target is to achieve one complete cycle at $0.08 \mathrm{rads}, 0.08 \mathrm{rads}, 0.05 \mathrm{rads}$, and $0.03 \mathrm{rads}$ of total rotation respectively, regardless of loading protocol.

\section{LINK TESTING - RESULTS}

Most of the primary links met their target rotation with the exception of the primary links (i.e., those with the haunch end connection) with $\rho=1.6$ and one primary link with $\rho=2.1$. Limit plastic rotations, $\gamma_{p l i m}$, for all specimens are shown versus normalized link in Fig. 5a. Link shear force versus rotation hysteresis curves for all links were generally symmetric, stable, and full prior to link fracture (Berman and Bruneau 2006). All primary links had a failure mode of flange fracture near the flange haunch weld, which in all but two links occurred prior to $20 \%$ strength degradation from local buckling. The fractures were found to originate primarily in the web-to-flange weld adjacent to the web haunch. This is in contrast to the fracture of the flange in the proof-of-concept experiment (Berman and Bruneau 2007), which was found to have originated in the flange itself. The difference is likely due to the web haunch plates located at the outer edges of the flange for the primary links, where the proof-of-concept test had a gusset at mid-width of the flange, away from the web-to-flange weld. 


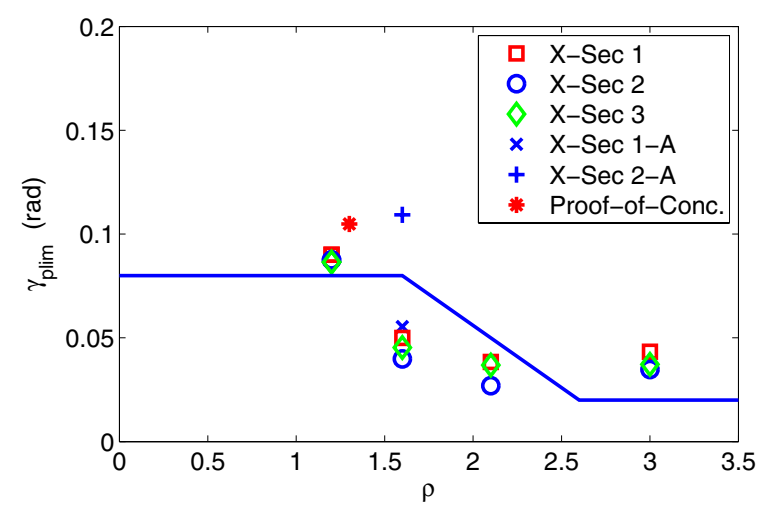

(a)

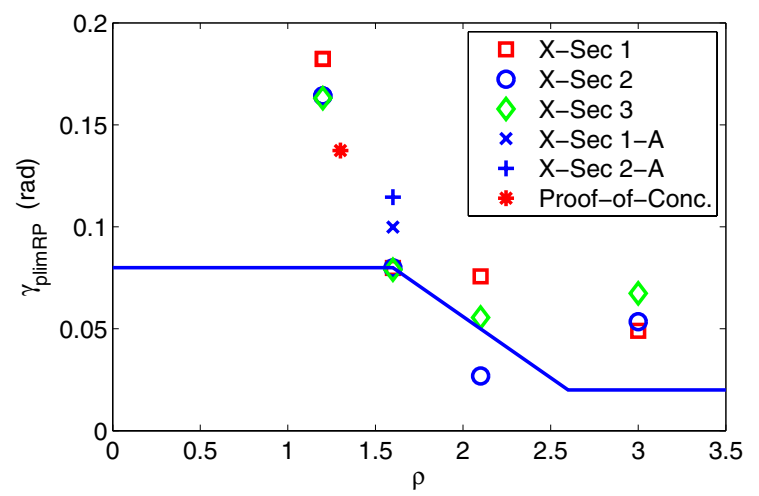

(b)

Figure 5. Limit Plastic Rotation versus Normalized Link Length (a) Experimental Results (b) Projected for 2005 Loading Protocol

Research by Richards and Uang (2003) indicated that the loading protocol for EBF links in the 2002 AISC Seismic Provisions is overly demanding in terms of the number of high rotation cycles it requires. As such, they proposed a new loading protocol that has been adopted in the 2005 AISC Seismic Provisions that more realistically represents the maximum rotation demand EBF links must sustain. In light of this recent change, it is worthwhile to investigate what rotations might be achieved if the new loading protocol had been used for the testing of the hybrid rectangular links with haunch end connections. Furthermore, as mentioned above, the difference in rotation demand for the loading protocols could provide insight into why the primary links with $\rho=1.6$ failed to reach their target rotation.

Using cumulative energy dissipation and/or cumulative plastic rotation, it is possible to estimate the rotation that might have been achieved if the 2005 loading protocol had been used. These two parameters were chosen because they may be useful for fracture prediction using stress intensity factors or strain controlled low cycle fatigue, respectively. Details regarding this procedure can be found in Berman and Bruneau (2006) and it is similar to one used by Okazaki et al. (2005) to interpret data from tests on WF links.

Fig. $5 \mathrm{~b}$ shows the projected rotations versus the normalized link length considering cumulative plastic rotation, respectively. As shown, the only link not projected to reach its target rotation using cumulative plastic rotation is Specimen X2L2.1, which does not satisfy the proposed design requirements.

The supplementary links were developed to investigate the effect of the end connection and loading protocol. AX1L1.6 had the modified end connection but was tested using the loading protocol from the 2002 AISC Seismic Provisions. AX2L1.6 had the modified end connection and was tested under the loading protocol from the 2005 AISC Seismic Provisions. The change in end connection from Specimen X1L1.6 to Specimen AX1L1.6 resulted in only a slightly larger limit rotation but considerably more cumulative plastic rotation. The change in loading protocol from the 2002 protocol for Specimen AX1L1.6 to the 2005 protocol for Specimen AX2L1.6 resulted in a significant increase in limit rotation. These specimens had the same cumulative plastic rotation and similar energy dissipation, yet Specimen AX2L1.6 reached a rotation of 0.123 rads using the 2005 loading protocol while Specimen AX1L1.6 only reached 0.068 rads under the 2002 loading protocol. Additionally, the proof-of-concept link, which had a shorter 
normalized length than the supplementary specimens, achieved a rotation of 0.123 rads using a loading protocol that is between the 2002 and 2005 loading protocols in terms of cumulative plastic rotation demand. Therefore, it seems that the difference in loading protocol intensity is largely responsible for the difference in obtained limit rotations.

To verify the procedure for projecting rotations for the 2005 loading protocol it is possible to compare the projected plastic limit rotation for X2L1.6 (0.082 rads) and the actual plastic limit rotation of AX2L1.6 (0.123 rads). Since the latter was tested using the 2005 loading protocol and both had identical cross-sections and lengths, it appears that the projection procedure may actually be conservative as it projects a significantly lower rotation for X2L1.6 than was actually acheived with AX2L1.6. Note the end connection differed for these specimens as well, however, that difference is not likely to account for more than 0.02 rads of increased plastic limit rotation, which was the difference between the projected limit rotation for AX1L1.6 and X1L1.6 (specimens that were both tested under the 2002 loading protocol and had different end connections).

Considering the data presented, it appears that links satisfying the proposed design criteria will achieve their target rotation if connections similar to the proof-of-concept test are used (i.e., connections that do not overly restrain the plastic flow in the link flanges), and if they are tested using the loading protocol from the 2005 AISC Seismic Provisions rather than the protocol from the 2002 provisions.

\section{CONCLUSIONS}

A new self-stabilizing tubular link for eccentrically braced frames has been developed. Links designed according the proposed requirements above were shown, experimentally and analytically, to have the ductility to achieve their target rotations under quasi-static cyclic loading as specified by the 2005 AISC loading protocol when end connections are used that do not overly restrain the plastic flow in the link flanges.

The compactness requirements in the AISC Seismic Provisions for hollow structural sections were not derived considering the use of these cross-sections as links in eccentrically braced frames. Therefore, web and flange compactness requirements have been proposed for tubular sections used in this manner. The proposed requirements for webs of tubular sections used as shear links allow a considerably larger compactness ratio than currently allowed by AISC as long as stiffeners are present. Proposed stiffener spacing for tubular links is also different from the current requirements for links utilizing wide-flange shapes in that they are only required for shear links, not intermediate and flexural links.

\section{ACKNOWLEDGEMENT}

This research was conducted by the State University of New York at Buffalo and was supported by the Federal Highway Administration under contract number DTFH61-98-C00094 to the Multidisciplinary Center for Earthquake Engineering Research. However, any opinions, findings, conclusions, and recommendations presented in this paper are those of the authors and do not necessarily reflect the views of the sponsors. Travel support for the first author was provided by the University of Washington. 


\section{REFERENCES}

AISC (2002). "Seismic Provisions for Structural Steel Buildings." American Institute of Steel Construction, Chicago, IL.

AISC (2005). "Seismic Provisions for Structural Steel Buildings." American Institute of Steel Construction, Chicago, IL.

ATC (1992). "Guidelines for Seismic Testing of Components of Steel Structures." Report-24, Applied Technology Council, Redwood City, CA.

Berman, J.W., and Bruneau, M. (2005a). "Supplemental System Retrofit Considerations for Braced Steel Bridge Piers." J. of Earthquake Engineering and Structural Dynamics, 34(4 and 5), 497-517.

Berman, J. W., and Bruneau, M., (2005b). "Approaches for the Seismic Retrofit of Braced Steel Bridge Piers and Proof-of-Concept Testing of a Laterally Stable Eccentrically Braced Frame." Technical Report MCEER-05-0004, Multidisciplinary Center for Earthquake Engineering Research, Buffalo, NY.

Berman, J. W., and Bruneau, M., (2006). "Further Development of Tubular Eccentrically Braced Frame Links for the Seismic Retrofit of Braced Steel Truss Bridge Piers.” Technical Report MCEER-06-0006, Multidisciplinary Center for Earthquake Engineering Research, Buffalo, NY.

Berman, J.W., and Bruneau, M., (2007). "Experimental and Analytical Investigation of Tubular Links for Eccentrically Braced Frames." Engineering Structures, (In Press, accepted 11/06).

Dusicka, P., Itani, A.M., and Buckle, I.G. (2002). "Cyclic Behavior of Shear Links and Tower Shaft Assembly of San Francisco-Oakland Bay Bridge Tower." Technical Report CCEER 02-06, Center for Civil Engineering Earthquake Research, University of Nevada Reno, Reno, NV.

Engelhardt, M. D., and Popov, E. P. (1992). "Experimental Performance of Long Links in Eccentrically Braced Frames.” J. Struc. Eng., 118(11), pp. 3067-3088.

Hjelmstad, K. D., and Popov, E. P. (1983). "Cyclic Behavior and Design of Link Beams.” J. Struc. Eng., 109(10), pp. 2387-2403.

Hjelmstad, K. D., and Popov, E. P. (1984). "Characteristics of Eccentrically Braced Frames.” J. Struc. Eng., 110(2), pp. 340-353.

HKS (2001). "ABAQUS Standard User's Manual.” Hibbitt, Karlsson, and Sorensen, Inc., Pawtucket, RI.

Itani, A.M. (1997). "Cyclic Behavior of Richmond-San Rafael Tower Links.” Technical Report CCEER 974, Center for Civil Engineering Earthquake Research, University of Nevada Reno, Reno, NV.

Kasai, K., and Popov, E. P. (1986a). "Study of Seismically Resistant Eccentrically Braced Steel Frame Systems." Report No. UCB/EERC-86/01, Earthquake Engineering Research Center, College of Engineering, University of California Berkeley, Berkeley, CA.

Kasai, K., and Popov, E. P. (1986b). "General Behavior of WF Steel Shear Link Beams." J. Struc. Eng., 112(2), pp. 362-382.

Malley, J. O., and Popov, E. P. (1984). "Shear Links in Eccentrically Braced Frames." J. Struc. Eng., 110(9), pp. 2275-2295.

Okazaki, T., Arce, G, Ryu, H. C., and Engelhardt, M. D., (2005). "Experimental Study of Local Buckling, Overstrength, and Fracture of Links in Eccentrically Braced Frames." J. Struc. Eng., 131(10), pp. 15261535.

Popov, E. P., and Bertero, V. V (1980). "Seismic Analysis of Some Steel Building Frames." J. of the Eng. Mech. Div., 106(1), pp. 75-92.

Richards, P., and Uang, C. M. (2003). "Development of Testing Protocol for Short Links in Eccentrically Braced Frames." Report No. SSRP-2003/08, Structural Systems Research Project, Department of Structural Engineering, University of California San Diego, La Jolla, CA.

Ricles, J. M., and Popov, E. P. (1989). "Composite Action in Eccentrically Braced Frames.” J. Struc. Eng., 115(8), pp. 2046-2066.

Roeder, C. W., and Popov, E. P. (1978a). "Eccentrically Braced Steel Frames for Earthquakes." J. Struc. Eng., 104(3), pp. 391-412.

Roeder, C. W., and Popov, E. P. (1978b). "Cyclic Shear Yielding of Wide-Flange Beams." J. of the Eng. Mech. Div., 104(4), pp. 763-780. 